\title{
Measurement of momentum flux using two meteor radars in Indonesia
}

\author{
Naoki Matsumoto ${ }^{1}$, Atsuki Shinbori ${ }^{1}$, Dennis M. Riggin ${ }^{2}$, and Toshitaka Tsuda ${ }^{1}$ \\ ${ }^{1}$ Research Institute for Sustainable Humanosphere (RISH), Kyoto University, \\ Uji, 611-0011, Kyoto, Japan \\ ${ }^{2}$ GATS Inc., 3360 Mitchell Lane, Boulder, CO 80301, USA \\ Correspondence to: Toshitaka Tsuda (tsuda@rish.kyoto-u.ac.jp)
}

Received: 18 September 2015 - Revised: 15 March 2016 - Accepted: 15 March 2016 - Published: 24 March 2016

\begin{abstract}
Two nearly identical meteor radars were operated at Koto Tabang $\left(0.20^{\circ} \mathrm{S}, 100.32^{\circ} \mathrm{E}\right)$, West Sumatra, and Biak $\left(1.17^{\circ} \mathrm{S}, 136.10^{\circ} \mathrm{E}\right)$, West Papua, in Indonesia, separated by approximately $4000 \mathrm{~km}$ in longitude on the Equator. The zonal and meridional momentum flux, $u^{\prime} w^{\prime}$ and $v^{\prime} w^{\prime}$, where $u, v$, and $w$ are the eastward, northward, and vertical wind velocity components, respectively, were estimated at 86 to $94 \mathrm{~km}$ altitudes using the meteor radar data by applying a method proposed by Hocking (2005). The observed $u^{\prime} w^{\prime}$ at the two sites agreed reasonably well at 86, 90, and $94 \mathrm{~km}$ during the observation periods when the data acquisition rate was sufficiently large enough. Variations in $v^{\prime} w^{\prime}$ were consistent between 86,90 , and $94 \mathrm{~km}$ altitudes at both sites. The climatological variation in the monthly averaged $u^{\prime} w^{\prime}$ and $v^{\prime} w^{\prime}$ was investigated using the long-term radar data at Koto Tabang from November 2002 to November 2013. The seasonal variations in $u^{\prime} w^{\prime}$ and $v^{\prime} w^{\prime}$ showed a repeatable semiannual and annual cycles, respectively. $u^{\prime} w^{\prime}$ showed eastward values in February-April and July-September and $v^{\prime} w^{\prime}$ was northward in June to August at 90-94 km, both of which were generally anti-phase with the mean zonal and meridional winds, having the same periodicity. Our results suggest the usefulness of the Hocking method.
\end{abstract}

Keywords. Meteorology and atmospheric dynamics (middle atmosphere dynamics)

\section{Introduction}

The interaction of various atmosphere waves with the background mean zonal winds is known to produce interesting wind variability in the middle atmosphere $(10-100 \mathrm{~km})$ as well as in the mesosphere and lower thermosphere (MLT) region $(60-150 \mathrm{~km})$ (e.g., Holton, 1983). In the equatorial atmosphere, the wave-mean flow interaction drives the quasibiennial oscillation (QBO) in the lower stratosphere (e.g., Plumb, 1977), and a 6-month periodicity of zonal winds is also produced in the upper stratosphere and the mesosphere, which is called the stratosphere semiannual oscillation (S$\mathrm{SAO}$ ) and mesosphere semiannual oscillation (M-SAO), respectively (Groves, 1972; Hirota, 1978).

The M-SAO becomes westward twice a year, centered in January to April and August to September. However, a peculiar behavior of M-SAO was found by satellite and radar observations; that is, the westward phase of M-SAO was significantly enhanced only in January to April every 2 or 3 years (for example in 1993, 1995, 1997, 2000, and 2002) (Burrage et al., 1996; Garcia et al., 1997; Isoda et al., 2004; Sridharan et al., 2007; de Wit et al., 2013). This phenomenon was referred to as the mesospheric QBO (M-QBO), which was reported to essentially synchronize with the stratospheric QBO (Sridharan et al., 2007). However, M-QBO is different from the stratospheric QBO, which has an irregular periodicity of 22-34 months, in that the westward wind enhancement of M-QBO always occurred only in January to April, being synchronous with a seasonal cycle. Therefore, this phenomenon is also called the mesospheric quasi-biennial enhancement (M-QBE) (Venkateswara Rao et al., 2012b).

It has also been reported from medium-frequency (MF) radar observations at Pameungpeuk $\left(7.4^{\circ} \mathrm{S}, 107.4^{\circ} \mathrm{E}\right)$, West 
Java, Indonesia, that the westward enhancement of M-QBO coincided with large values of wind velocity variance with short-period (20-120 min) perturbations (Venkateswara Rao et al., 2012a). Recently, Moss et al. (2016) studied the MSAO during the early months of 2002 and 2006 when the westward excursion of the M-SAO was enhanced. These periods coincided with increased negative zonal gravity wave momentum flux. The enhancement of momentum flux was significant but not related to increased convective activity or a different configuration in the underlying winds. Therefore, atmospheric gravity waves seem to affect the enhancement of westward wind velocity of M-QBO (e.g., Garcia and Sassi, 1999; Ern et al., 2015). In order to further understand the role of gravity waves in generating the M-QBO, we need to investigate the vertical flux of zonal momentum $\left(u^{\prime} w^{\prime}\right)$, where $u$ ' and $w^{\prime}$ are the fluctuating components of zonal (eastward) and vertical wind velocity, respectively.

Vincent and Reid (1983) developed a unique radar technique to measure $u^{\prime} w^{\prime}$ in the MLT region using the Buckland Park MF radar, South Australia. A pair of narrow antenna beams were steered into the opposite azimuth direction, and then $u^{\prime} w^{\prime}$ was estimated by subtracting the radial wind velocity variance. This beam-pair method was also applied to the middle and upper atmosphere radar (the MU radar) in Japan, and the wave drag force was inferred in the mesosphere, which agreed well with theoretical prediction (Tsuda et al., 1990). Thus, the beam-pair method was verified as an accurate method to determine $u^{\prime} w^{\prime}$. However, this technique can only be applied to a large atmospheric radar with multiple antenna beams, which are few in number in the world.

Hocking (2005) proposed another radar technique to measure momentum flux using a much simpler meteor radar. A meteor radar transmits VHF radio waves into wide directions, and detects scattering from an ionized meteor trail at $70-110 \mathrm{~km}$ altitude. The arrival angles of meteor echoes are determined by an interferometer receiving system. The antenna array is fairly compact, consisting of several crossed Yagi antennas. Fritts et al. (2010) applied this Hocking method to the Southern Argentina Agile Meteor Radar (SAAMER; $53.8^{\circ} \mathrm{S}, 67.8^{\circ} \mathrm{W}$ ) for estimating $u^{\prime} w^{\prime}$. Andrioli et al. (2013) also analyzed $u^{\prime} w^{\prime}$ from meteor radar observations at Cachoeria Paulista $\left(23^{\circ} \mathrm{S}, 45^{\circ} \mathrm{W}\right)$, Brazil, using the Hocking method. Thus, this technique is becoming widely used. Andrioli et al. (2015) analyzed long-term characteristics of the momentum flux using three meteor radar results at Cachoeria Paulista $\left(23^{\circ} 5,45^{\circ} \mathrm{W}\right)$, São João Do Cariri $\left(7^{\circ} \mathrm{S}\right.$, $\left.36^{\circ} \mathrm{W}\right)$, and Santa Maria ( $\left.30^{\circ} \mathrm{S}, 54^{\circ} \mathrm{W}\right)$. Fritts et al. (2012) carried out modeling studies and concluded that conventional meteor radars that are used for this study are capable of momentum flux measurements. However, monthly estimates can only be made at heights with the highest meteor cut and with errors of $20-50 \%$.

The Hocking method is now widely used to study the behavior of momentum flux in the MLT region. However, Vincent et al. (2010) raised questions about the accuracy of the
Hocking method, claiming unclarified issues on the assumption of this technique, such as a necessary number of meteor echoes and a small contribution of vertical winds on the radial wind velocity because of wide antenna view angles. According to Vincent et al. (2010), momentum flux has a much wider distribution of values than any single component of the wind. Therefore, long averaging is needed to determine the mean value. The authors discuss that the averaging period of $u^{\prime} w^{\prime}$ should be longer than 1 month to obtain meaningful results. Note that Hocking (2005) suggested that more than 30 meteors are sufficient in $1 \mathrm{~h}$.

It is assumed that the background mean winds are uniform over the entire radar observation area in the height-time bin of $4 \mathrm{~km}$ and $2 \mathrm{~h}$. However, this assumption may not be always justified, because the antenna scan range of a meteor radar is $10-45^{\circ}$, which is much wider than that for the beam-pair method (normally less than $10^{\circ}$ ). Moreover, because of large zenith angles, the contribution of the vertical wind velocity component to the radial winds becomes relatively smaller, which is not beneficial for accurate $u^{\prime} w^{\prime}$ determination.

It seems difficult to show a deductive verification of the Hocking method; therefore, in this study, we compared the results of $u^{\prime} w^{\prime}$ and $v^{\prime} w^{\prime}$ determinations from two meteor radars, both located on the Equator at Koto Tabang and Biak, Indonesia, with a longitudinal separation of approximately $4000 \mathrm{~km}$. We also analyzed the climatological variations in $u^{\prime} w^{\prime}$ and $v^{\prime} w^{\prime}$ employing long-term meteor radar data collected at Koto Tabang from 2002 to 2013.

We describe in Sect. 2 the experimental setup of the two meteor radar systems in Indonesia. We also show the fundamental performance of the meteor echo observations, and a method for calculation of mean wind velocity from radial meteor winds. Section 3 concisely introduces the measurement technique proposed by Hocking (2005) for determining the momentum flux from meteor winds. The analyzed results are shown in Sect. 4, which presents two major issues. First, we compare the momentum flux between the two meteor radars in Indonesia, aiming at validation of the Hocking method. Secondly, we analyze momentum flux from 11-year meteor radar data at Koto Tabang, and discuss seasonal variations in momentum flux and mean winds.

\section{Meteor wind radars in Koto Tabang and Biak, Indonesia}

A meteor radar has been operated within the observatory of the Equatorial Atmosphere Radar (EAR) (Fukao et al., $2003)$ in Koto Tabang, West Sumatra, Indonesia $\left(0.20^{\circ} \mathrm{S}\right.$, $100.32^{\circ} \mathrm{E}, 865 \mathrm{~m}$ a.s.l.), as a joint project between RISH and the Indonesian National Institute of Aeronautics and Space (LAPAN) since November 2002. Another meteor radar, with the same system specifications, was installed at the LAPAN observatory in Biak, West Papua, Indonesia $\left(1.17^{\circ} \mathrm{S}\right.$, $136.10^{\circ} \mathrm{E}, 45 \mathrm{~m}$ a.s.l.), in May 2011. 
The transmitting frequencies of the meteor radars at Koto Tabang and Biak are 37.70 and $33.32 \mathrm{MHz}$, respectively, with a peak transmitting power of $13 \mathrm{~kW}$. Details of the meteor radar system at Koto Tabang are described in Batubara et al. (2011). The meteor radars detect meteor echoes at 70$110 \mathrm{~km}$ altitude, and the location of meteor trails is determined by an interferometer receiving system. Because a single crossed Yagi antenna is used for transmission, pointed to the zenith, we detect meteor echoes in any azimuth direction. Elevation angles of echoes normally range widely, but only meteor echoes between 10 and $45^{\circ}$ zenith angles were accepted.

The daily total meteor echo counts varied from 8000 to 12000 per day in July 2005 at Koto Tabang, and the mean hourly echo rate was 330-500. The height distribution of the meteor echoes shows a bell shape at 70-110 km altitude. We averaged meteor echo rate for the Koto Tabang radar results in 2002-2013, and found that the number of meteor echoes became a maximum at approximately $89 \mathrm{~km}$ with a half-amplitude width of about $5.5 \mathrm{~km}$. The meteor echo rate was reduced to 78 and $60 \%$ at 86 and $94 \mathrm{~km}$, respectively, relative to the value at $90 \mathrm{~km}$. The local time dependence of the meteor echo rate showed a diurnal variation, although it was not a clear sinusoidal curve; however, an enhanced peak appeared at 06:00 LT (local time), and a relatively broader minimum occurred at 17:00-18:00. The ratio of the hourly meteor echo rate between minimum and maximum ranged from approximately 5.9 to 6.0 at 86 and $94 \mathrm{~km}$, and it was as large as 9.0 at $90 \mathrm{~km}$. Because the data rate rapidly decreases below approximately $80 \mathrm{~km}$ and above $100 \mathrm{~km}$, we limited the height range for our analysis to $78-102 \mathrm{~km}$.

A meteor radar detects the radial wind velocity for individual meteor trails that appear sporadically with random directions. We calculated the zonal and meridional wind velocities from the radial winds in a height-time bin of $4 \mathrm{~km}$ and $2 \mathrm{~h}$, assuming a constant and uniform wind in the bin and no vertical wind velocity. When the number of meteor echoes in each bin was less than five, we did not calculate the horizontal wind velocity. The two meteor radars at Koto Tabang and Biak have nearly the same system configuration, and were manufactured by the same company (Genesis Software Pty Ltd). The horizontal separation of the radars provides a unique opportunity to compare similarities and differences in the wind field over the equatorial region. Unfortunately, the observation periods coincided for only 3 years from 2011 to 2013. In particular, we can compare the results of $u^{\prime} w^{\prime}$ and $v^{\prime} w^{\prime}$ obtained from these meteor radars by employing the Hocking method. One of the major contributions of this study is to validate the Hocking technique.

The meteor radar at Koto Tabang accumulated long-term radar data for 11 years from November 2002 to November 2013, which are archived in the data storage and exchange system called the Inter-University Upper Atmosphere Global Observation Network (IUGONET) (Hayashi et al., 2013; Abe et al., 2014). We investigated the climatological characteristics of $u^{\prime} w^{\prime}$ and $v^{\prime} w^{\prime}$ variations in the equatorial MLT region.

\section{Application of the hocking method for calculating momentum flux}

The Hocking (2005) technique for estimating momentum flux with a meteor radar is an appealingly simple concept. However, a large matrix needs to be inverted to obtain the momentum flux components. The technique will not be fully described here, since Hocking (2005) does this in detail. The technique is based on least-squares minimization of the quantity

$\Lambda=\sum\left(v_{r}^{2}-\bar{v}_{r}^{2}\right)^{2}$,

where

$v_{r}=u \sin \theta \cos \varphi+v \sin \theta \sin \varphi+w \cos \theta$

is the radial wind velocity in the direction with the elevation $(\theta)$ and azimuth $(\varphi)$ angles. Here the overbar denotes timeaveraged wind estimates that are resolved into the individual meteor detection angles. Note that time-averaged velocity estimates are derived with conventional meteor radar processing where $w$ is assumed to be zero.

We compared $u^{\prime} w^{\prime}$ and $v^{\prime} w^{\prime}$ as observed at Koto Tabang and Biak in 2011-2013. We first selected the time interval for data analysis as $2 \mathrm{~h}$, covering $1 \mathrm{~h}$ each before and after the nominal time, and the nominal time was shifted every $1 \mathrm{~h}$. The thickness of a height bin was $4 \mathrm{~km}$, and the center of the bin was shifted every $2 \mathrm{~km}$ from 80 to $100 \mathrm{~km}$; therefore, the successive bins partially overlap each other. When the number of meteor echoes was less than 30 in the $2 \mathrm{~h} \times 4 \mathrm{~km}$ bin, we discarded that bin. We finally selected the results in five height bins centered at $86,88,90,92$, and $94 \mathrm{~km}$, considering smaller meteor echo rate below/above $86 / 94 \mathrm{~km}$. Note that the lowest and highest bins correspond to the height range at 84-88 and 92-96 km.

We first determined monthly mean $u^{\prime} w^{\prime}$ and $v^{\prime} w^{\prime}$ for all available periods. We used the monthly mean data for investigation of long-term variations in momentum flux as well as their frequency spectral analysis when the number of bins was greater than 100 in each month.

\section{Results and discussion}

\subsection{Comparison of the momentum flux between the two meteor radars}

Figure 1 shows comparison of the observed momentum flux between Biak and Koto Tabang from January 2011 to November 2013. Figure 1a and b show the monthly mean $u^{\prime} w^{\prime}$ and $v^{\prime} w^{\prime}$, respectively, at 86,90 , and $94 \mathrm{~km}$ altitudes. 

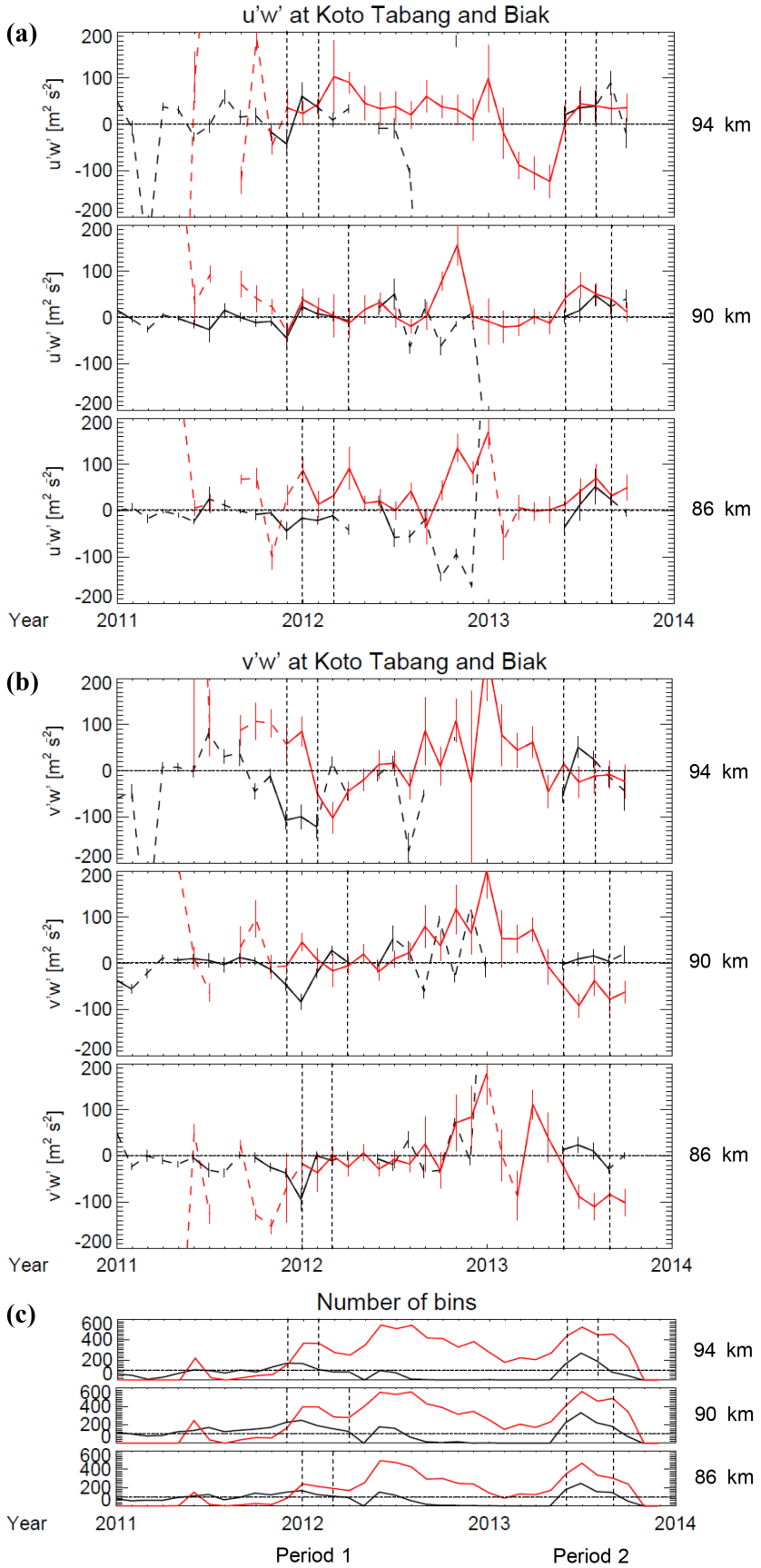

Figure 1. Monthly mean (a) $u^{\prime} w^{\prime}$ and (b) $v^{\prime} w^{\prime}$ at Koto Tabang (black line) and Biak (red line) at 86,90 , and $94 \mathrm{~km}$, and (c) the number of bins used to determine $u^{\prime} w^{\prime}$ and $v^{\prime} w^{\prime}$ at 86,90 , and $94 \mathrm{~km}$. Error bars of $u^{\prime} w^{\prime}$ and $v^{\prime} w^{\prime}$ indicate the $95 \%$ confidence interval. The solid line for $u^{\prime} w^{\prime}$ and $v^{\prime} w^{\prime}$ corresponds to the observation period when the number of bins was larger than 100 , while the dashed line for $u^{\prime} w^{\prime}$ and $v^{\prime} w^{\prime}$ indicate the period with the fewer than 100 bins. The vertical dotted lines show the observation period when the number of bins was greater than 100 for both sites at each altitude.
In Fig. 1c we show the number of bins in each month at 86, 90 , and $94 \mathrm{~km}$. The Biak meteor radar started operation in May 2011, and the number of bins became stably large after December 2011. On the other hand, the Koto Tabang meteor radar stopped operation in May 2012 and became unstable from September 2012 to May 2013. Therefore, unfortunately, the two radars were simultaneously operated in two short periods: (i) from December 2011 to April 2012 and (ii) from June 2013 to September 2013. Solid lines in Fig. 1a and b correspond to observation periods when the number of bins was greater than 100, while dashed lines indicate the observation periods when this criterion was not satisfied. Note that duration of the analysis period varied at different altitudes, being narrower at 86 and $94 \mathrm{~km}$.

During period (i), $u^{\prime} w^{\prime}$ over Koto Tabang and Biak shows a similar variation at the three heights, with agreement being best at $90 \mathrm{~km}$. The variation in $u^{\prime} w^{\prime}$ agreed better during period (ii) at all three heights. Earlier studies of stratospheric gravity waves over the maritime continent that used GPS radio occultation temperature data indicated that the horizontal extent of both tropical convection and stratospheric gravity wave activity was wide enough to cover the whole of Indonesia (e.g., Tsuda et al., 2009). Therefore, we consider the excitation source of gravity waves to be similar between Biak and Koto Tabang, although the magnitude of the generation sources may have some regional differences, depending on intensity of tropical convection.

The distribution of horizontal propagation directions of gravity waves in the MLT region is predicted to become azimuthally inhomogeneous because of the filtering effects due to wave-mean flow interaction by QBO and S-SAO (e.g., Plumb, 1977; Garcia and Sassi, 1999). Therefore, the dominant direction of $u^{\prime} w^{\prime}$ near the mesopause also depends on season. Because the filtering mechanism of gravity waves is caused by the global-scale dynamics, such as QBO and SSAO, we can expect the behavior of $u^{\prime} w^{\prime}$ to be similar within $4000 \mathrm{~km}$ along the Equator. The results in Fig. 1 indicate a reasonable agreement of the observed $u^{\prime} w^{\prime}$ between Biak and Koto Tabang.

On the other hand, we may not expect similar behavior of $v^{\prime} w^{\prime}$ between the two radar sites, because there are no common mechanisms to affect meridional propagation directions of gravity waves. Therefore, $v^{\prime} w^{\prime}$ may not necessarily be correlated between Biak and Koto Tabang. The results of $v^{\prime} w^{\prime}$ in Fig. 1, however, show consistency at the three heights at each radar site.

\subsection{Seasonal variations in the momentum flux}

Figure 2 shows the monthly mean $u^{\prime} w^{\prime}$ and $v^{\prime} w^{\prime}$ at 86 to $94 \mathrm{~km}$ altitude obtained from the meteor radar at Koto Tabang from 2002 to 2013. We estimated the variation range of $u^{\prime} w^{\prime}$ and $v^{\prime} w^{\prime}$, obtained using more than 100 bins as $\mu \pm \sqrt{2} \sigma$ ( $\mu$ : mean value; $\sigma:$ standard deviation). The results for $u^{\prime} w^{\prime}$ and $v^{\prime} w^{\prime}$ at $90 \mathrm{~km}$ were from -35 to $+42 \mathrm{~m}^{2} \mathrm{~s}^{-2}$ 

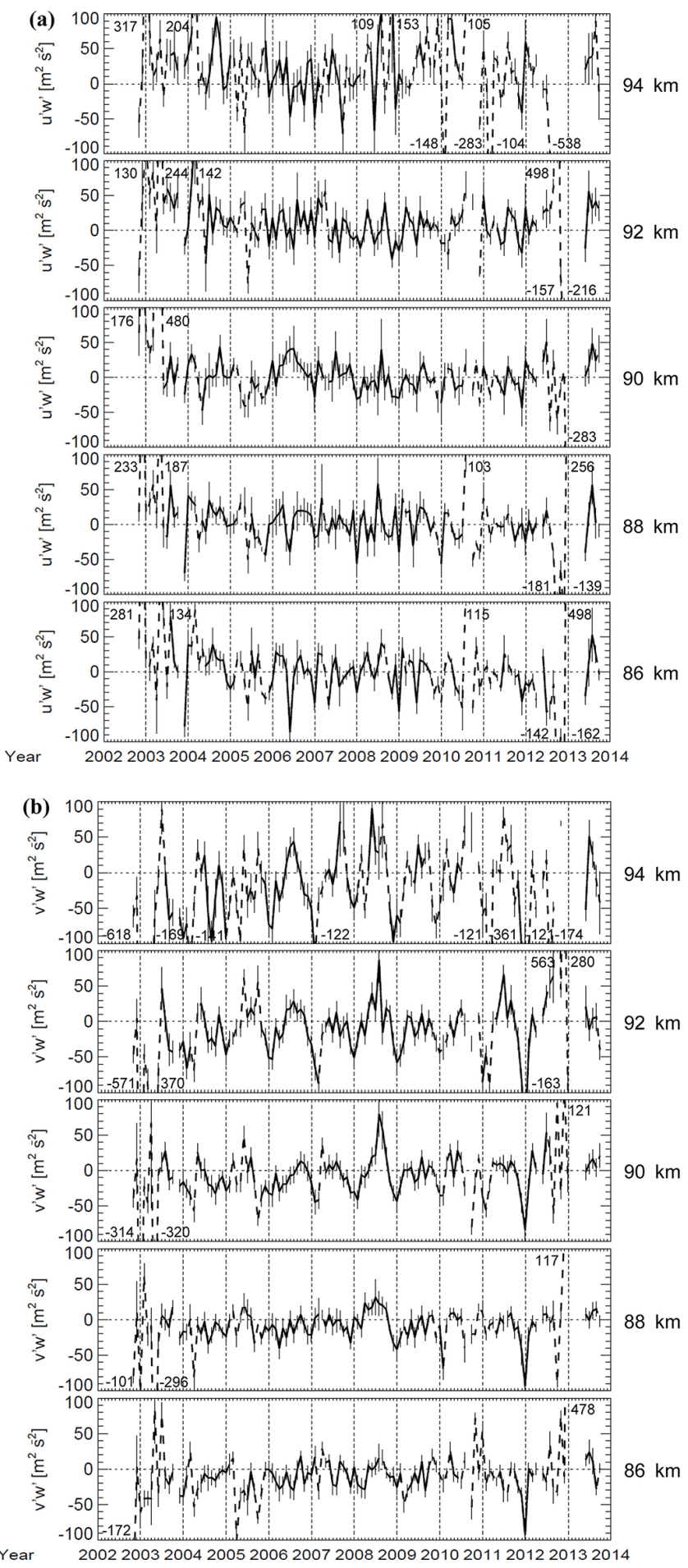

Figure 2. Monthly mean (a) $u^{\prime} w^{\prime}$ and (b) $v^{\prime} w^{\prime}$ obtained from the meteor radar at Koto Tabang from November 2002 to November 2013 at $86-94 \mathrm{~km}$. Solid and dashed lines show $u^{\prime} w^{\prime}$ and $v^{\prime} w^{\prime}$ when the number of bins was larger or smaller than 100 , respectively. The numbers in each panel indicate an exceeded value. (a)
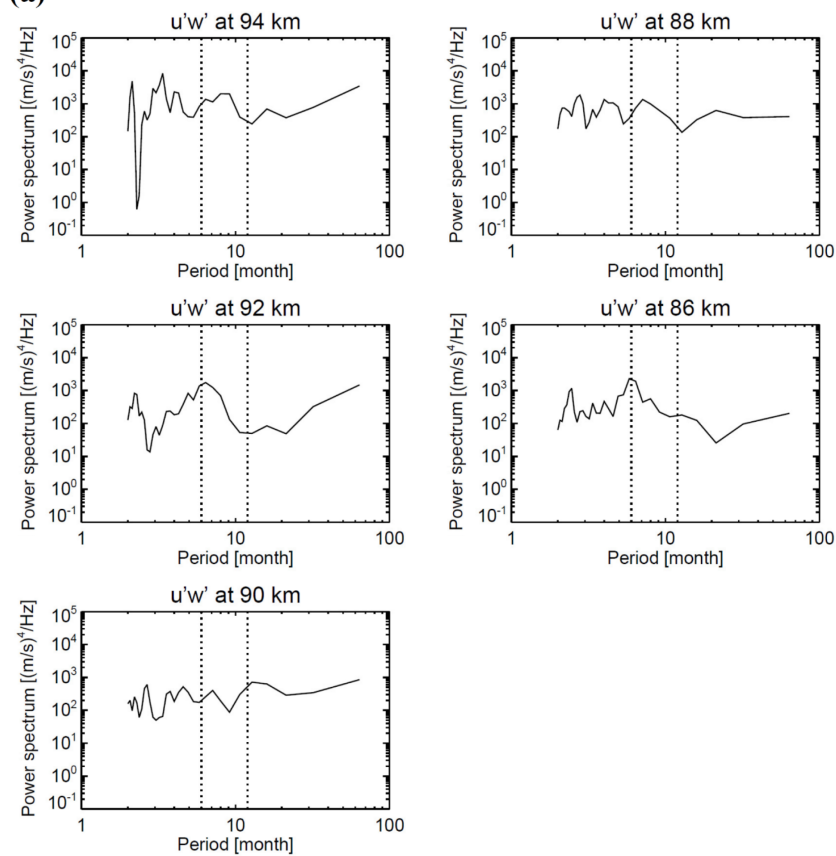

(b)
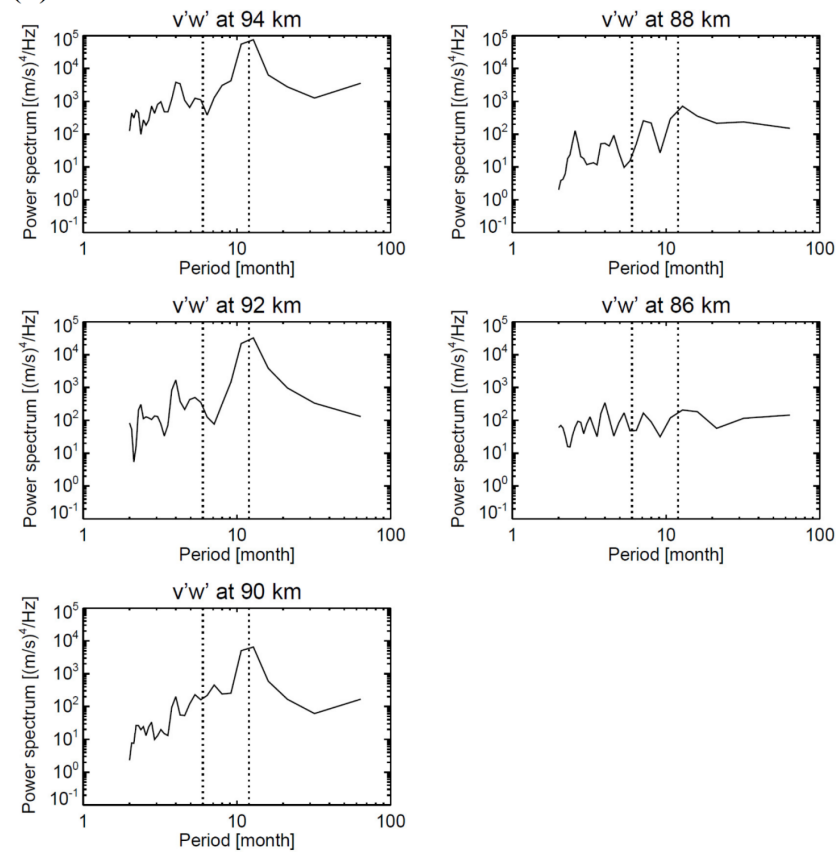

Figure 3. Power spectrum of (a) $u^{\prime} w^{\prime}$ and (b) $v^{\prime} w^{\prime}$ at $86-94 \mathrm{~km}$ altitudes at Koto Tabang. The two dashed lines in each panel indicate periodicity of 6 and 12 months, respectively.

and from -41 to $+28 \mathrm{~m}^{2} \mathrm{~s}^{-2}$, respectively. The amplitudes of the momentum flux at $90 \mathrm{~km}$ were relatively smaller compared with those at other heights. Later we show statistics of $u^{\prime} w^{\prime}$ and $v^{\prime} w^{\prime}$ by averaging the results in Fig. 2.

In Fig. 2a, the values of $u^{\prime} w^{\prime}$ at $86 \mathrm{~km}$ had local maxima in February to March and August to September during 
(a)
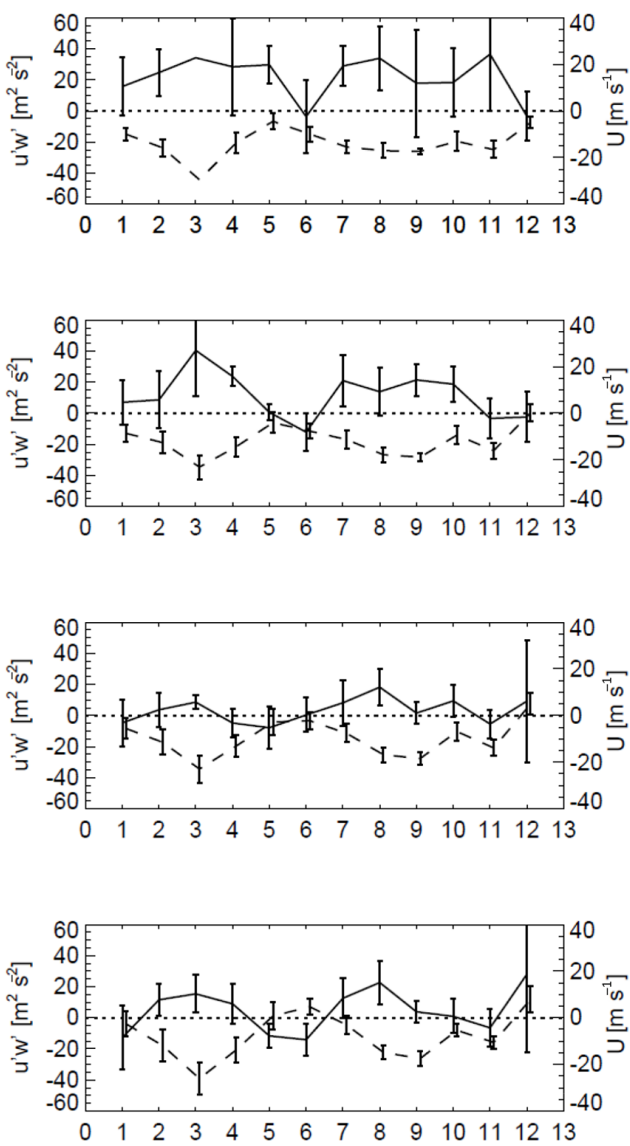

$88 \mathrm{~km}$

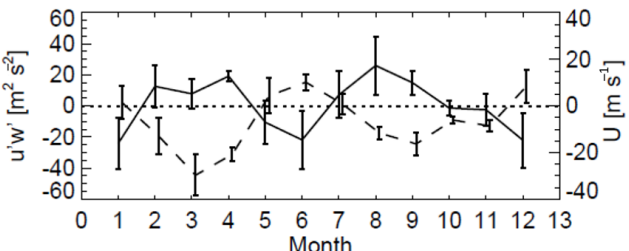

(b)
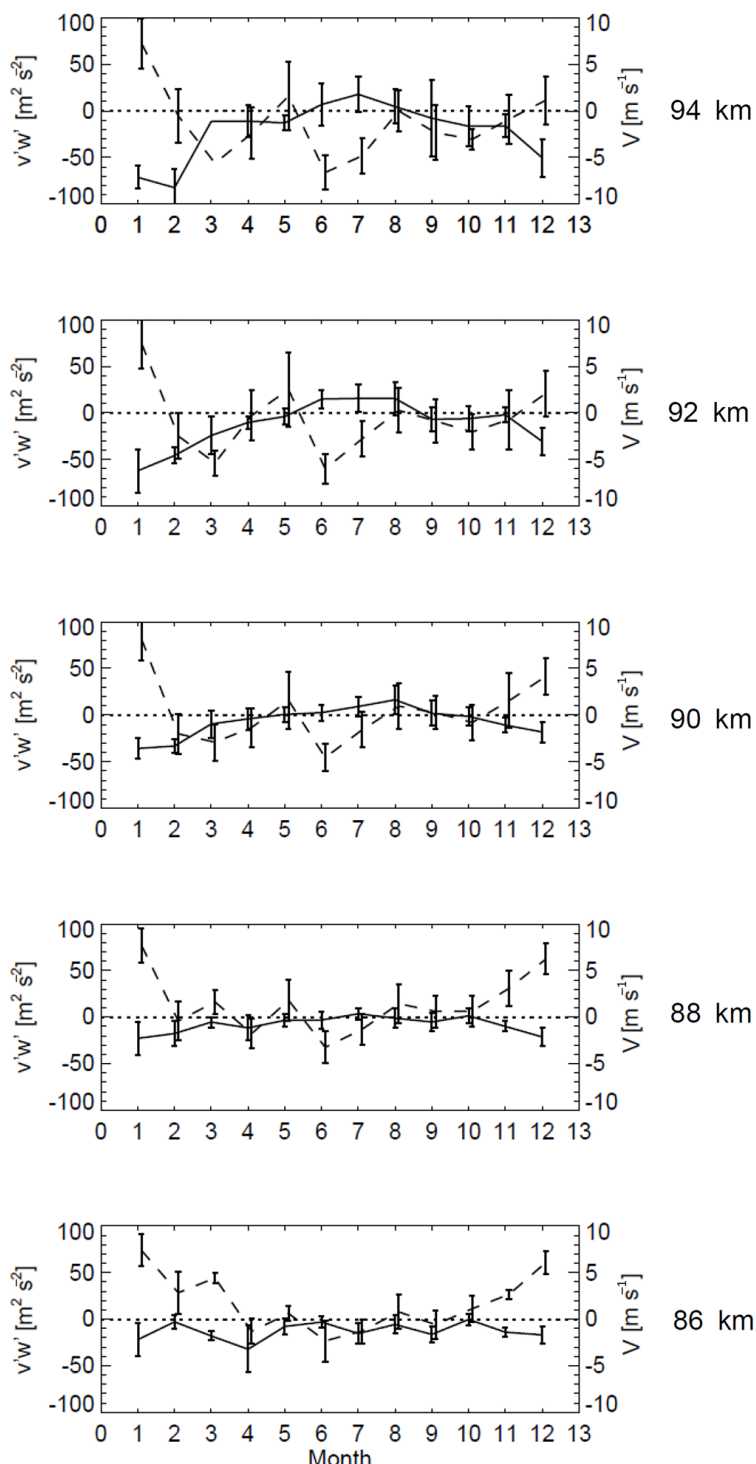

Figure 4. Seasonal variation in (a) $u^{\prime} w^{\prime}$ (solid line) and mean zonal (eastward) wind velocity $(U)$ (dashed line), and (b) $v^{\prime} w^{\prime}$ (solid line) and mean meridional (northward) wind velocity $(V)$ (dashed line) at 86-94 km after calculating the monthly mean values in 2002-2013 at Koto Tabang. Error bars show the $95 \%$ confidence interval.

Table 1. Mean value, standard deviation $(\sigma)$, and variation range of $u^{\prime} w^{\prime}$ and $v^{\prime} w^{\prime}$ at the height range of 86-94 km at Koto Tabang.

\begin{tabular}{lrrrrrr}
\hline $\begin{array}{l}\text { Altitude } \\
{[\mathrm{km}]}\end{array}$ & $\begin{array}{r}\text { Mean of } u^{\prime} w^{\prime} \\
{\left[\mathrm{m}^{2} \mathrm{~s}^{-2}\right]}\end{array}$ & $\begin{array}{r}\sigma \text { of } u^{\prime} w^{\prime} \\
{\left[\mathrm{m}^{2} \mathrm{~s}^{-2}\right]}\end{array}$ & $\begin{array}{r}\text { Range of } u^{\prime} w^{\prime} \\
{\left[\mathrm{m}^{2} \mathrm{~s}^{-2}\right]}\end{array}$ & $\begin{array}{r}\text { Mean of } v^{\prime} w^{\prime} \\
{\left[\mathrm{m}^{2} \mathrm{~s}^{-2}\right]}\end{array}$ & $\begin{array}{r}\sigma \text { of } v^{\prime} w^{\prime} \\
{\left[\mathrm{m}^{2} \mathrm{~s}^{-2}\right]}\end{array}$ & $\begin{array}{r}\text { Range of } v^{\prime} w^{\prime} \\
{\left[\mathrm{m}^{2} \mathrm{~s}^{-2}\right]}\end{array}$ \\
\hline 94 & 21.8 & 13.6 & $2.6-41.0$ & -20.8 & 31.0 & $-64.6-23.0$ \\
92 & 11.5 & 14.6 & $-9.2-32.1$ & -12.1 & 24.5 & $-46.7-22.6$ \\
90 & 3.0 & 7.9 & $-8.2-14.2$ & -6.9 & 15.8 & $-29.2-15.4$ \\
88 & 4.9 & 14.1 & $-15.0-24.8$ & -8.0 & 8.7 & $-20.3-4.3$ \\
86 & 0.4 & 17.0 & $-23.7-24.5$ & -12.9 & 9.3 & $-26.0-0.3$ \\
\hline
\end{tabular}


Table 2. Cross-correlation coefficient and time lag between momentum flux and mean horizontal wind at the height range of 86-94 km at Koto Tabang.

\begin{tabular}{lrrrr}
\hline $\begin{array}{l}\text { Altitude } \\
{[\mathrm{km}]}\end{array}$ & $\begin{array}{r}\text { Cross-correlation coefficient } \\
\text { between } u^{\prime} w^{\prime} \text { and } U\end{array}$ & $\begin{array}{r}\text { Time lag } \\
\text { [month] }\end{array}$ & $\begin{array}{r}\text { Cross-correlation coefficient } \\
\text { between } v^{\prime} w^{\prime} \text { and } V\end{array}$ & $\begin{array}{r}\text { Time lag } \\
\text { [month] }\end{array}$ \\
\hline 94 & -0.58 & 0.0 & -0.67 & -0.4 \\
92 & -0.68 & 0.0 & -0.51 & -1.0 \\
90 & -0.70 & 1.0 & -0.56 & -0.4 \\
88 & -0.50 & 1.0 & -0.64 & -0.4 \\
86 & -0.77 & 0.0 & -0.29 & -2.5 \\
\hline
\end{tabular}

2006-2010, whereas they had local minima in June to July and December to January in the same period. A semiannual oscillation in the $u^{\prime} w^{\prime}$ was present at $86 \mathrm{~km}$. However, $v^{\prime} w^{\prime}$ in Fig. 2b exhibited an annual cycle with northward maximum in June-August, which became more evident at higher altitudes. Large values sometimes appeared, and they were consistent between different height regions.

We investigated the dominant periodicity of $u^{\prime} w^{\prime}$ and $v^{\prime} w^{\prime}$ shown in Fig. 2 by applying a frequency spectral analysis. Figure 3 shows power spectra of $u^{\prime} w^{\prime}$ and $v^{\prime} w^{\prime}$ at 86 to $94 \mathrm{~km}$ altitude over Koto Tabang. In this calculation, we used the monthly mean $u^{\prime} w^{\prime}$ and $v^{\prime} w^{\prime}$ when the number of bins is greater than 100 in each month. The power spectrum of $u^{\prime} w^{\prime}$ at $86 \mathrm{~km}$ had a peak at a 6 -month period, i.e., a semiannual oscillation. At $92 \mathrm{~km}$, the period was slightly longer than 6 months. On the other hand, the spectral peak at a 6month period was not clearly found at other heights. The frequency spectrum of $v^{\prime} w^{\prime}$ shows a clear peak at 12 months above $90 \mathrm{~km}$, while shorter periodicities are also recognized at 86 and $88 \mathrm{~km}$, in addition to the annual cycle.

In order to investigate a seasonal variation in $u^{\prime} w^{\prime}$ and $v^{\prime} w^{\prime}$, we calculated the climatological mean from the observed results in Fig. 2. In each month, we averaged all available monthly results in 2002-2013. Figure 4 shows $u^{\prime} w^{\prime}$ and $v^{\prime} w^{\prime}$ at $86,88,90,92$, and $94 \mathrm{~km}$, where the number of total months for available data was $80,93,97,95$, and 68 months out of a total of 133 months, respectively.

The mean eastward $(U)$ and northward $(V)$ mean wind velocities are also plotted in Fig. 4. In Fig. 4a, $u^{\prime} w^{\prime}$ at $86 \mathrm{~km}$ was eastward in February to April and July to September, and westward in May to June and October to January, respectively. The seasonal variation in $u^{\prime} w^{\prime}$ at this height indicated a clear semiannual oscillation as suggested in Fig. 3. This feature can be seen also in a height range of up to $92 \mathrm{~km}$. On the other hand, $u^{\prime} w^{\prime}$ was almost always eastward at $94 \mathrm{~km}$ throughout a year.

Figure $4 \mathrm{~b}$ show results for $v^{\prime} w^{\prime}$ and $V$, in which an annual cycle was recognized for $v^{\prime} w^{\prime}$ above $90 \mathrm{~km}$. The meridional wind, $V$, also shows a clear annual cycle at all heights, but shorter periodicity, such as 4 months, overlaps at 92 and $94 \mathrm{~km}$.
Statistics of $u^{\prime} w^{\prime}$ and $v^{\prime} w^{\prime}$ shown in Fig. 4 are summarized in Table 1, showing the annual mean value, standard deviation $(\sigma)$, and the range of variations at five altitudes. $u^{\prime} w^{\prime}$ was biased toward east at all heights, with $\sigma$ ranging from approximately 8 to $17 \mathrm{~m}^{2} \mathrm{~s}^{-2}$. However, $v^{\prime} w^{\prime}$ was negative (southward) in the entire height ranges.

The half-year cycle of $u^{\prime} w^{\prime}$ in Fig. 4 suggests that MSAO is related to gravity waves. We calculated the crosscorrelation function (CCF) between $u^{\prime} w^{\prime}$ and the eastward wind velocity in Fig. 4. The CCF analysis summarized in Table 2 indicates a clear anti-phase relation between $u^{\prime} w^{\prime}$ and $U$. The large magnitude of negative CCF values was detected with a time lag of 0.0 to 1.0 months. Anti-phase relation between $v^{\prime} w^{\prime}$ and $V$ was also seen in Table 2 with a time lag of 0.4 to 2.5 months.

The monthly mean $u^{\prime} w^{\prime}$ at $86-92 \mathrm{~km}$ altitude in Fig. 4 generally ranged from approximately -25 to $+40 \mathrm{~m}^{2} \mathrm{~s}^{-2}$ as in Table 1. Using the beam-pair method with the MU radar, Tsuda et al. (1990) reported that mean $u^{\prime} w^{\prime}$ at $70 \mathrm{~km}$ ranged from approximately -1 to $+2 \mathrm{~m}^{2} \mathrm{~s}^{-2}$ for perturbations with periods from $5 \mathrm{~min}$ to $2 \mathrm{~h}$. If gravity waves do not attenuate through vertical propagation, the magnitude of $u^{\prime} w^{\prime}$ increases as $\exp (z / H)$, where $z$ and $H$ are the altitude and the scale height. Assuming $\mathrm{H}$ is $6 \mathrm{~km}$, the increase from 70 to $90 \mathrm{~km}$ becomes $\exp (20 / 6) \sim 28$. We can infer that $u^{\prime} w^{\prime}$ could range from -28 to $+56 \mathrm{~m}^{2} \mathrm{~s}^{-2}$, which shows a reasonable agreement with the observed $u^{\prime} w^{\prime}$ at $90 \mathrm{~km}$ at Koto Tabang.

\section{Concluding remarks}

In order to test the new method to derive the momentum flux with a meteor radar (Hocking, 2005), we compared $u^{\prime} w^{\prime}$ and $v^{\prime} w^{\prime}$ at $86-94 \mathrm{~km}$ between Koto Tabang and Biak, Indonesia, both located on the Equator. Because these meteor radars have the same observation system, the effects of instrumental bias are minimized, and therefore similarity in the results suggests that statistical errors in the measurements are being overcome.

The $u^{\prime} w^{\prime}$ variations agreed reasonably well during the period when the number of bins used to derive $u^{\prime} w^{\prime}$ was more than 100. Likewise, $v^{\prime} w^{\prime}$ at both sites behaved consistently at successive heights. This suggests that the wave momen- 
tum flux was effectively determined by the Hocking method. We also investigated a climatological variation in $u^{\prime} w^{\prime}$ and $v^{\prime} w^{\prime}$ using the long-term observation data at Koto Tabang in 2002-2013. Spectral analysis of $u^{\prime} w^{\prime}$ indicated a semiannual cycle at most heights, which was clearly recognized at 86 and $92 \mathrm{~km}$. The $u^{\prime} w^{\prime}$ variation at $86 \mathrm{~km}$ altitude showed a clear seasonal variation with eastward (February to April and July to September) and westward (May to June and October to January) directions. As the observation height increased, the amplitude of the seasonal variation in $u^{\prime} w^{\prime}$ became small, and $u^{\prime} w^{\prime}$ at $94 \mathrm{~km}$ height is directed mostly eastward for over a year. The seasonal variation in $v^{\prime} w^{\prime}$ was dominated by an annual cycle, in particular above $90 \mathrm{~km}$ altitudes. Good (antiphase) correlation between the seasonal cycle of momentum flux and the mean winds was recognized for both zonal and meridional components.

Although the accuracy of the Hocking method (2005) is controversial (Vincent et al., 2010), we found consistency of the momentum flux observed with two meteor radars in Indonesia, verifying the relevance of this method. Many meteor radars operated worldwide can be used to study the effects of gravity waves in driving the general circulation and longperiod oscillations of zonal winds near the mesopause, which will contribute to clarifying atmospheric coupling processes.

Acknowledgements. This work is supported by KAKENHI grant number 22253006. We used the wind data observed with the two meteor radars operated at the LAPAN's observatory in Koto Tabang and Biak, Indonesia, where the latter was provided by National Institute of Information and Communications Technology (NICT). We are grateful to Effendy Acmad, Rizal Suryana, Clara Yatini, and colleagues of LAPAN for operating the meteor radars. D. M. Riggin thanks RISH for support during a five-month visit during 2014-15. This study is also supported by the Future Development Funding Program of Kyoto University Research Coordination Alliance. We deeply acknowledge Prof. Iain Reid for valuable comments. The radar data are archived in the IUGONET system at http://database. rish.kyoto-u.ac.jp/arch/iugonet/index-idr.html.

The topical editor, A. J. Kavanagh, thanks the two anonymous referees for help in evaluating this paper.

\section{References}

Abe, S., Umemura, N., Koyama, Y., Tanaka, Y., Yagi, M., Yatagai, A., Shinbori, A., UeNo, S., Sato, Y., and Kaneda, N.: Progress of the IUGONET system - metadata database for upper atmosphere ground-based observation data, Earth Planets Space, 66, 133, doi:10.1186/1880-5981-66-133, 2014.

Andrioli, V. F., Fritts, D. C., Batista, P. P., and Clemesha, B. R.: Improved analysis of all-sky meteor radar measurements of gravity wave variances and momentum fluxes, Ann. Geophys., 31, 889908, doi:10.5194/angeo-31-889-2013, 2013.

Andrioli, V. F., Batista, P. P., Clemesha, B. R., Schuch, N. J., and Buriti, R. A.: Multi-year observations of gravity wave momentum fluxes at low and middle latitudes inferred by all-sky me- teor radar, Ann. Geophys., 33, 1183-1193, doi:10.5194/angeo33-1183-2015, 2015.

Batubara, M., Suryana, T., Manik, T., and Sitompul, P.: Koto Tabang - West Sumatera Meteor Radar: System Design and Initial Results of a Large Scale Meteor Echo, The 6th International Conference on Telecommunication Systems, Services, and Applications, 20-21 October 2011, Bali Denpasar, Indonesia, 1721, doi:10.1109/TSSA.2011.6095399, 2011.

Burrage, M. D., Vincent, R. A., Mayr, H. G., Skinner, W. R., Arnold, N. F., and Hays, P. B.: Long-term variability in the equatorial middle atmosphere zonal wind, J. Geophys. Res., 101, 1284712854, 1996.

de Wit, R. J., Hibbins, R. E., Espy, P. J., and Mitchell, N. J.: Interannual variability of mesopause zonal winds over Ascension Island: Coupling to the stratospheric QBO, J. Geophys. Res.-Atmos., 118, 12052-12060, doi:10.1002/2013JD020203, 2013.

Ern, M., Preusse, P., and Riese, M.: Driving of the SAO by gravity waves as observed from satellite, Ann. Geophys., 33, 483-504, doi:10.5194/angeo-33-483-2015, 2015.

Fritts, D. C., Janches, D., and Hocking, W. K.: Southern Argentina Agile Meteor Radar: Initial assessment of gravity wave momentum fluxes, J. Geophys. Res., 115, D19123, doi:10.1029/2010JD013891, 2010.

Fritts, D. C., Janches, D., Hocking, W. K., Mitchell, N. J., and Taylor, M. J.: Assessment of gravity wave momentum flux measurement capabilities by meteor radars having different transmitter power and antenna configurations, J. Geophys. Res., 117, D10108, doi:10.1029/2011JD017174, 2012.

Fukao, S., Hashiguchi, H., Yamamoto, M., Tsuda, T., Nakamura, T., Yamamoto, M. K., Sato, T., Hagio, M., and Yabugaki, Y.: Equatorial Atmosphere Radar (EAR): System description and first results, Radio Sci., 38, 1053, doi:10.1029/2002RS002767, 2003.

Garcia, R. R., Dunkerton, T. J., Lieberman, R. S., and Vincent, R. A.: Climatology of the semiannual oscillation of the tropical middle atmosphere, J. Geophys. Res., 102, 26019-26032, 1997.

Garcia, R. R. and Sassi, F.: Modulation of the mesospheric semiannual oscillation by the quasibiennial oscillation, Earth Planets Space, 51, 563-569, 1999.

Groves, G. V.: Annual and semi-annual zonal wind components and corresponding temperature and density variations, $60-130 \mathrm{~km}$, Planet. Space Sci., 20, 2099-2112, 1972.

Hayashi, H., Koyama, Y., Hori, T., Tanaka, Y., Abe, S., Shinbori, A., Kagitani, M., Kouno, T., Yoshida, D., UeNo, S., Kaneda, N., Yoneda, M., Umemura, N., Tadokoro, H., Motoba, T., and IUGONET project team: Inter-university Upper Atmosphere Global Observation NETwork (IUGONET), Data Sci. J., 12, WDS179-WDS184, 2013.

Hirota, I.: Equatorial waves in the upper stratosphere and mesosphere in relation to the semiannual oscillation of the zonal wind, J. Atmos. Sci., 35, 714-722, 1978.

Hocking, W. K.: A new approach to momentum flux determinations using SKiYMET meteor radars, Ann. Geophys., 23, 2433-2439, doi:10.5194/angeo-23-2433-2005, 2005.

Holton, J. R.: The influence of gravity wave breaking on the general circulation of the middle atmosphere, J. Atmos. Sci., 40, 24972507, 1983.

Isoda, F. T., Tsuda, T., Nakamura, T., Vincent, R. A., Reid, I. M., Achmad, E., Sadewo, A., and Nuryanto, A.: Intraseasonal oscillations of the zonal wind near the mesopause observed with 
medium-frequency and meteor radars in the tropics, J. Geophys. Res., 109, D21108, doi:10.1029/2003JD003378, 2004.

Moss, A. C., Wright, C. J., Davis, R. N., and Mitchell, N. J.: Gravity-wave momentum fluxes in the mesosphere over Ascension Island $\left(8^{\circ} \mathrm{S}, 14^{\circ} \mathrm{W}\right)$ and the anomalous zonal winds of the semi-annual oscillation in 2002, Ann. Geophys., 34, 323-330, doi:10.5194/angeo-34-323-2016, 2016.

Plumb, R. A.: The Interaction of Two Internal Waves with the Mean Flow: Implications for the Theory of the Quasi-Biennial Oscillation, J. Atmos. Sci., 34, 1847-1858, doi:10.1175/15200469(1977)034<1847:TIOTIW> 2.0.CO;2, 1977.

Sridharan, S., Tsuda, T., and Gurubaran, S.: Radar observations of long-term variability of mesosphere and lower thermosphere winds over Tirunelveli $\left(8.7^{\circ} \mathrm{N}, 77.8^{\circ} \mathrm{E}\right)$, J. Geophys. Res., 112, D23105, doi:10.1029/2007JD008669, 2007.

Tsuda T., Murayama, Y., Yamamoto, M., Kato, S., and Fukao, S.: Seasonal variation of momentum flux in the mesosphere observed with the MU radar, Geophys. Res. Lett., 17, 725-728, 1990.

Tsuda, T., Ratnam, M. V., Alexander, S. P., Kozu, T., and Takayabu, Y.: Temporal and spatial distributions of atmospheric wave energy in the equatorial stratosphere revealed by GPS radio occultation temperature data obtained with the CHAMP satellite during 2001-2006, Earth Planets Space, 61, 525-533, 2009.
Venkateswara Rao, N., Tsuda, T., Riggin, D. M., Gurubaran, S., Reid, I. M., and Vincent, R. A.: Long-term variability of mean winds in the mesosphere and lower thermosphere at low latitudes, J. Geophys. Res., 117, A10312, doi:10.1029/2012JA017850, 2012a.

Venkateswara Rao, N., Tsuda, T., and Kawatani, Y.: A remarkable correlation between short period gravity waves and semiannual oscillation of the zonal wind in the equatorial mesopause region, Ann. Geophys., 30, 703-710, doi:10.5194/angeo-30-703-2012, 2012b.

Vincent, R. A., Kovalam, S., Reid, I. M., and Younger, J. P.: Gravity wave flux retrievals using meteor radars, Geophys. Res. Lett., 37, L14802, doi:10.1029/2010GL044086, 2010.

Vincent, R. A. and Reid, I. M.: HF Doppler measurements of mesospheric gravity wave momentum fluxes, J. Atmos. Sci., 40, 13211333, 1983. 